\title{
IMPACTOS NA BIODIVERSIDADE DO RIO OURICURÍ EM CAPANEMA-PA OCASIONADOS PELA DEMOGRAFIA URBANA NAS MARGENS DO RIO
}

André Luis Nascimento de Oliveira - andre-luis_oss@ hotmail.com Universidade Federal Rural da Amazônia Antonia Natalia Dias de Oliveira - antonianataliadias@ gmail.com Universidade Federal Rural da Amazônia Salma Saráty de Carvalho - salma.meioambiente@ gmail.com Universidade Federal Rural da Amazônia Williams Jorge da Cruz Macêdo - williamsmacedo@yahoo.com.br Universidade Federal Rural da Amazônia 


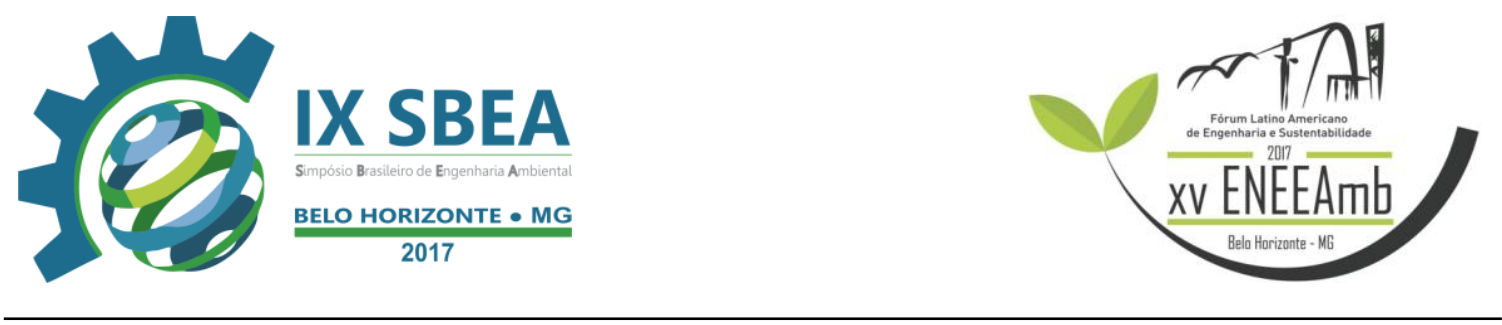

\section{RESUMO}

A qualidade da biodiversidade, de maneira geral, é diretamente influenciada pela qualidade do meio em que está inserida. É muito comum no Brasil a ocorrência de rios urbanos com a qualidade comprometida devido ao uso e ocupação desordenados. Este artigo apresenta os dados coletados na pesquisa em relação à ocupação urbana das margens do rio Ouricurí na cidade de Capanema-PA e possíveis impactos na biodiversidade do rio em questão, tendo os habitantes como fontes de informação. Foram realizadas 73 entrevistas no período de maio de 2016. A maioria dos entrevistados (86\%) afirmou que a quantidade de moradia no entorno do rio aumentou significativamente ao longo dos anos. Da mesma maneira, 69\% dos entrevistados disseram que houve modificação da vegetação nas margens deste rio. Bem como, 59\% descreveram uma diminuição do nível do rio nos últimos 5 anos. $70 \%$ dos indivíduos alegou que houve a diminuição na ocorrência de espécies de fauna aquática no rio, de maneira que $63 \%$ desconhece quaisquer motivos da diminuição. No que diz respeito às modificações na coloração da água, 77\% dos entrevistados assegurou o corpo hídrico tem se tornado mais turvo.

Palavras-chave: Diminuição da fauna e flora; ocupação desordenada; qualidade hídrica.

\section{INTRODUÇÃO/OBJETIVO}

Para Herculano e Silva (2015) a humanidade, historicamente, possui a necessidade do uso e exploração dos recursos disponíveis no meio ambiente para subsidiar seu modo de vida atual, isto é, visando utilizá-los como subsídios no processo de produção para o aumento do bem-estar. Diante do grande aumento populacional dado nos últimos séculos, percebe-se hoje a existência de inúmeros impactos no ambiente (KOMOGAWA, 2003).

Segundo Souza et al. (2014) a função desempenhada pela água é de extrema importância, tendo em vista que a mesma está inserida em todos os segmentos de observação (biológicos, sociais, econômicos e culturais), por esta razão é necessário ater-se de maneira cautelosa com a questão dos possíveis danos aos recursos hídricos disponíveis.

Segundo Guedes (2011) as aglomerações urbanas têm como um dos principais motivos proporcionar maior comodidade aos habitantes devido à carga tecnológica disponível nas mesmas, entretanto esse tipo de centro populacional é responsável por 


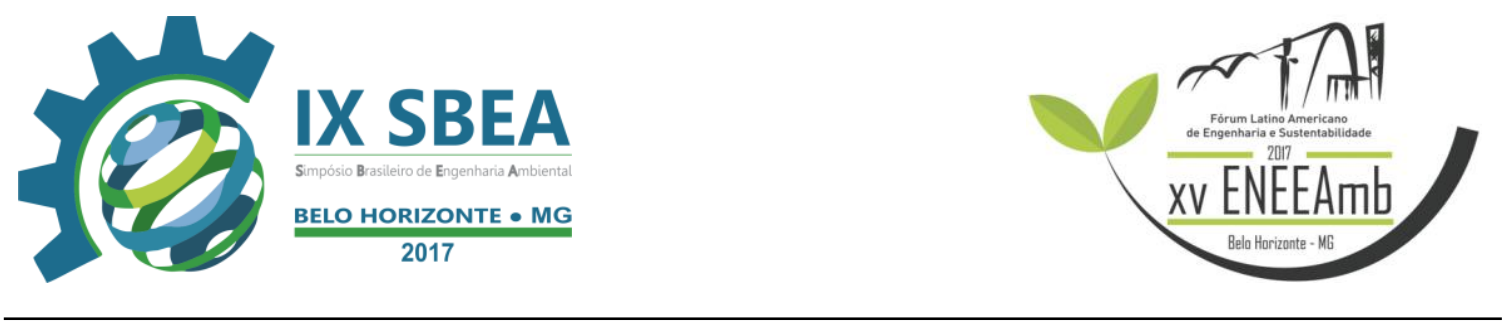

inúmeros problema sociais e ambientais, citando como exemplos os repositórios de lixo a céu aberto, a poluição e depreciação da qualidade de rios urbanos.

“O Brasil possui a maior rede potamográfica, a maior bacia hidrográfica e o maior rio do mundo" (ALMEIDA, 2010). Para Tucci (1997), a maneira como a urbanização brasileira se deu foi de modo desordenada e sem qualquer tipo de planejamento prévio, em ocorrência disto houve o desgaste e o agravamentos de problemas na malha fluvial urbana em todo o Brasil principalmente a partir dos anos 60 .

Independente de classe ou de diferenças, é normal que todas as pessoas busquem boa qualidade de vida, entretanto, os próprios costumes praticados pelos mesmos contradizem suas necessidades, tendo em vista que estes costumes tendem a diminuir a qualidade ambiental e dos recursos disponíveis do meio (MUCELIN; BELLINI, 2008).

Segundo Lima (2015) o modelo de crescimento observado na cidade de Capanema deu-se também sem planejamento (semelhante ao resto dos municípios brasileiros). A ocupação do território capanemense é marcada por uma notável supressão vegetal voltada para a disponibilização de locais habitáveis, tornando evidente a separação entre áreas urbanas e rurais. Ainda para o autor, esse processo em Capanema foi responsável por grande parte da degradação da fauna, flora e hidrografia.

Tendo em vista a importância da interdependência entre o meio e os componentes bióticos, este artigo visa demonstrar os resultados relacionados à ocupação humana e impactos na biodiversidade no rio Ouricurí em Capanema-PA de acordo com os dados coletados com os habitantes de áreas de influência do rio.

\section{METODOLOGIA}

O Município de Capanema ( $\left.01^{\circ} 11^{\prime} 45^{\prime \prime} \mathrm{S} ; 47^{\circ} 10^{\prime} 51^{\prime \prime} \mathrm{W}\right)$ se localiza no nordeste paraense, à $160 \mathrm{~km}$ distante da capital do estado, Belém. Capanema possui uma extensão territorial $614,693 \mathrm{~km}^{2}$, possui população estimada em 63.639 habitantes (IBGE, 2010).

A metodologia central para a coleta dos dados foi a realização de entrevistas com pessoas residentes nos bairros do município de Capanema em locais de até 50 metros próximos ao rio Ouricuri. A técnica de entrevista permite obter informação imediata e corrente sobre diversos assuntos de conhecimento do informante, permitindo 


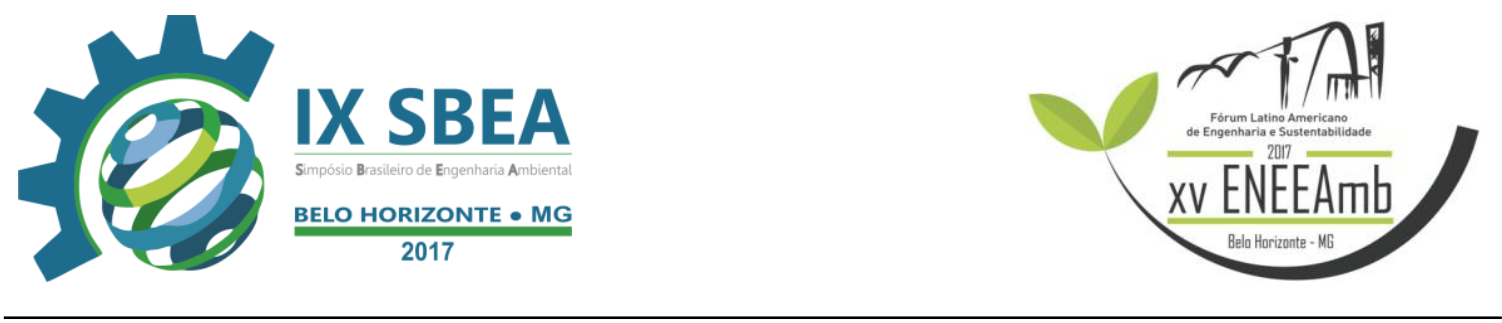

um aprofundamento do assunto abordado. No roteiro de entrevista utilizado constavam 24 perguntas, tanto questões abertas como fechadas conforme metodologia adotada por Lakatos e Marconi (2008).

No decorrer das entrevistas foram obtidas informações sobre questões socioeconômicas, bem como o conhecimento local sobre as questões ambientais referentes à ocupação das áreas próximas ao rio.

\section{RESULTADOS E DISCUSSÃO}

A partir da análise dos dados obtidos durante as entrevistas, foi possível observar que no decorrer dos últimos anos a quantidade de moradia no entorno do rio Ouricurí aumentou significativamente (86\%), sendo que nenhum entrevistado disse que o número de moradias diminuiu com o passar do tempo (Figura 1). 12\% dos entrevistados disseram que a quantidade de moradia continua a mesma e $2 \%$ não souberam responder ao questionamento. Souza (2003, p 2) afirma que "A maioria dos bairros cortados pelo rio caracteriza se como áreas residenciais pouco urbanizadas e apenas o Centro, onde se localiza a área comercial da cidade, apresenta um grau de urbanização mais intenso".

Carneiro (2010) corrobora com o autor quando afirma que o fenômeno das ocupações irregulares em margem de rios urbanos é um aspecto causado em decorrência do crescimento urbano desordenado, onde são somados aspectos negativos inerentes ao agente, bem como as consequências maléficas desse agente. Ainda no sentido da ocupação desordenada Martins (2006) diz que "O fenômeno de ocupação de áreas de proteção permanente decorre principalmente da falta de políticas públicas adequadas que garantam o acesso à habitação de interesse social". 

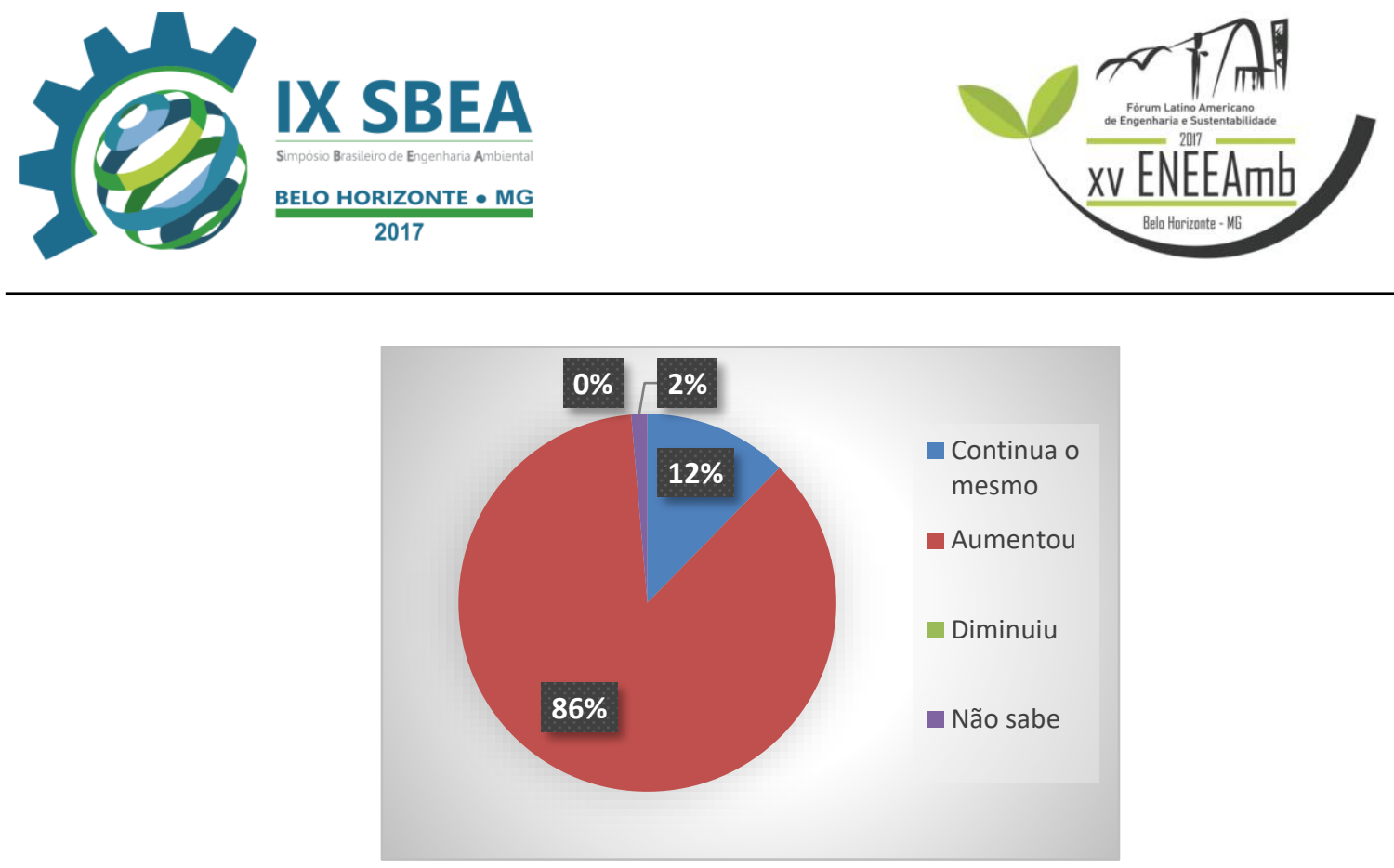

Figura 1: Gráfico que expressa a quantidade de moradia no entorno do rio Ouricurí. Fonte:

Autores.

Quando perguntado aos entrevistados: “A vegetação na margem do rio Ouricurí tem se modificado ao longo do tempo que você mora no local?” (Figura 2). 69\% disseram que sim, a vegetação foi modificada, 27\% afirmou que esta não foi modificada, $3 \%$ não souberam responder e $1 \%$ não respondeu.

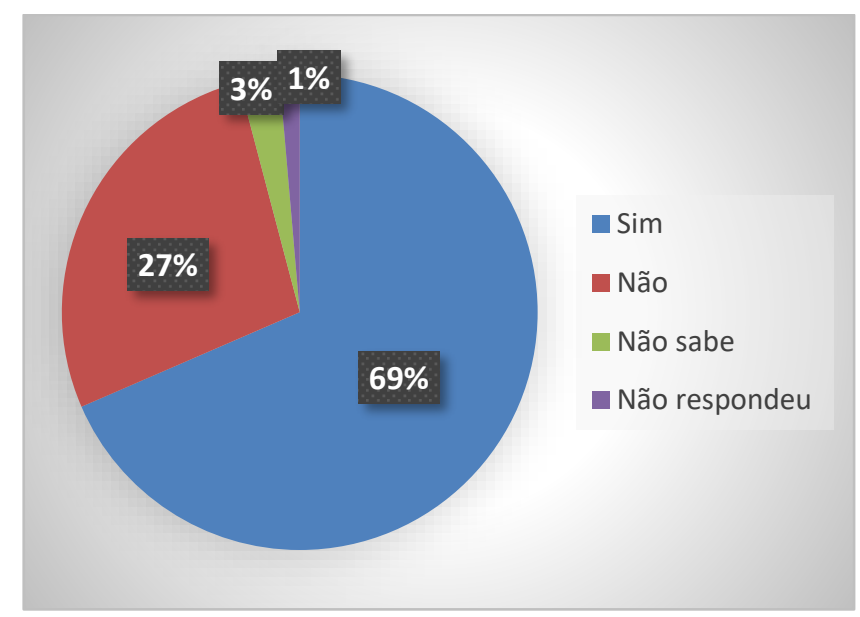

Figura 2: Gráfico que representa a modificação da vegetação nas margens do rio. Fonte: Autores.

O nível de água no rio Ouricurí, segundo os moradores entrevistados, passou por modificações ao longo dos anos (Figura 3). A maioria dos entrevistados (59\%) afirmaram que este nível diminuiu, $22 \%$ disseram que a quantidade de água aumentou, 
$15 \%$ acham que continua o mesmo, $3 \%$ não souberam responder ao questionamento e $1 \%$ não respondeu.

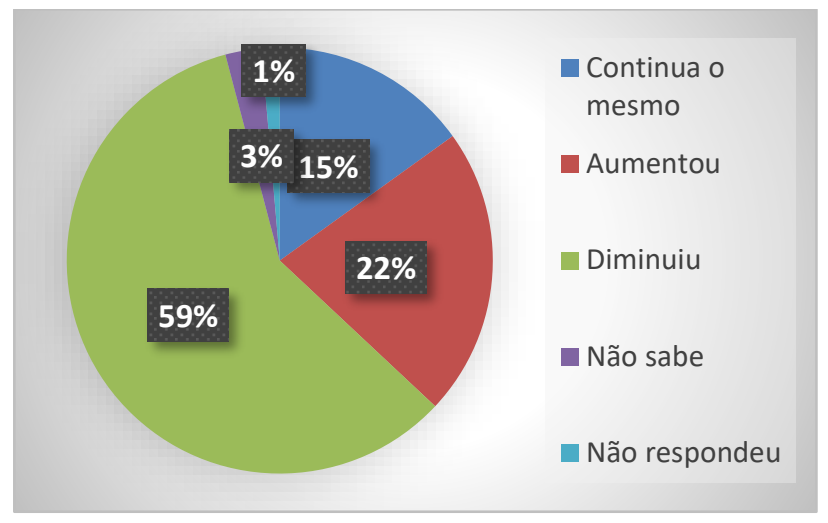

Figura 3: Gráfico o qual expressa a modificação do nível de água no rio. Fonte: Autores.

Os questionamentos que geraram os dois últimos gráficos possuem segundo Souza (2003) uma relação intima. Tal fato se torna evidente quando o autor afirma que:

“A redução da cobertura vegetal às margens do rio, ocasiona forte erosão e, consequentemente, o assoreamento do seu leito. Tal processo promove a diminuição da profundidade do canal, assim como a capacidade de contenção do volume d’água, que transborda, ocasionando o aumento da vazão e do número de enchentes".

Na figura 4 é demonstrado que 51 indivíduos (70\%) acredita que atualmente é baixa a quantidade de espécies de fauna aquática observada no rio Ouricurí, 15 indivíduos (22\%) acredita que há uma alta quantidade de espécies de fauna aquática, 7\% dos entrevistados acredita que não há incidência de nenhuma dessas espécies. 

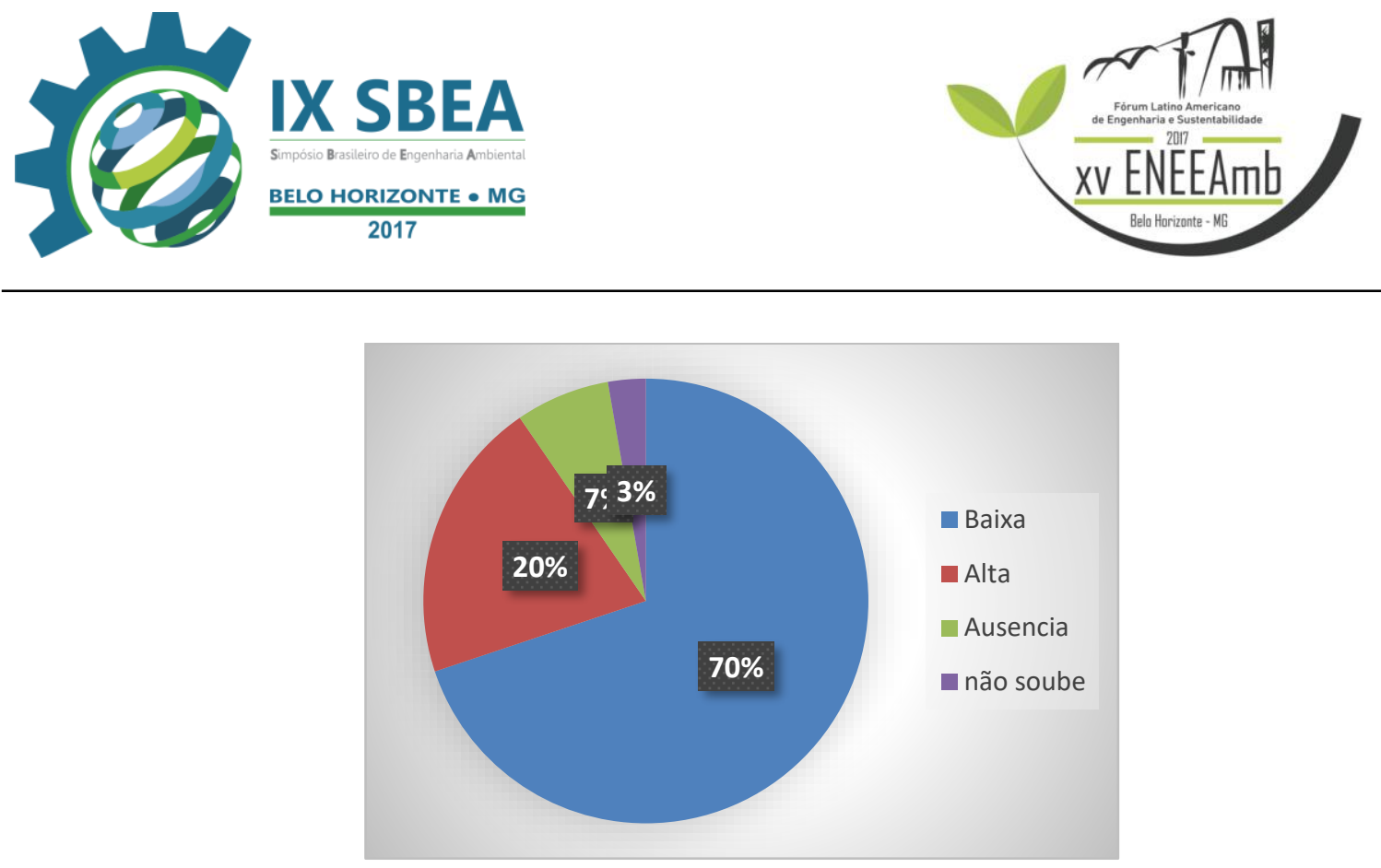

Figura 4: Quantidade espécies de fauna aquática no rio Ouricurí observada pelos moradores.

Fonte: Autores.

Para Soares (2012), uma das principais causas da diminuição e extinção de espécies é a fragilização do meio ao qual as mesmas estão inseridas, de maneira que o índice de poluição se relaciona diretamente com esta fragilização.

A figura 5 expressa os resultados das razões para a diminuição da fauna aquática no rio Ouricurí, percebeu-se que 46 indivíduos (63\%) nada sabem sobre as causas de uma possível diminuição de fauna, 18 indivíduos (24\%) acreditam que a poluição no rio causa a diminuição das espécies aquáticas e 3 moradores (4\%) acreditam que a ocupação das margens diminui a quantidades de espécies aquáticas.

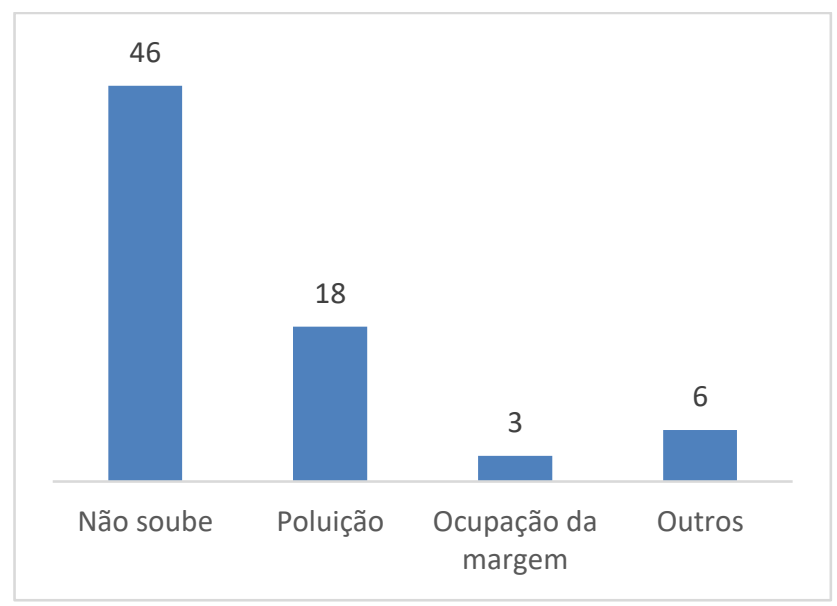

Figura 5: Motivos para a possível diminuição de espécies de fauna aquática. Fonte: Autores. 


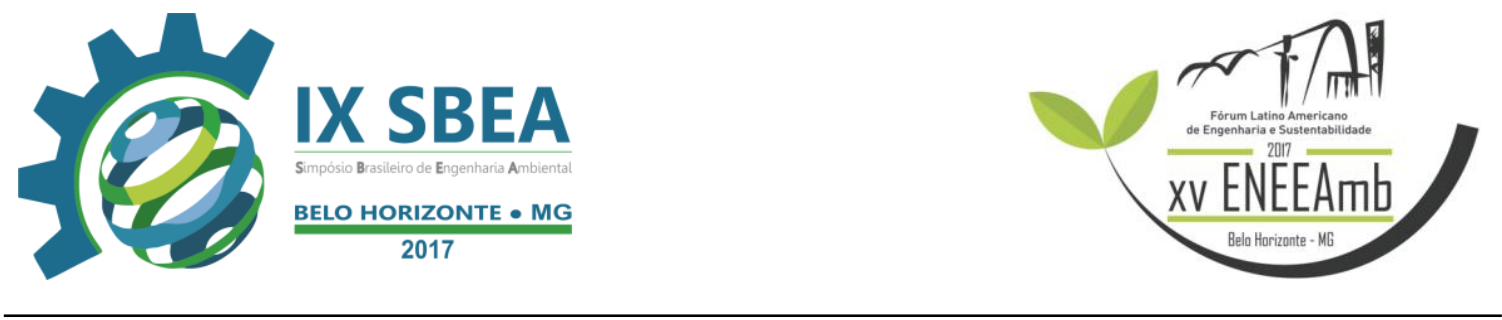

Montanha et al. (2011) afirmam que são crescentes os índices de poluição despejados no meio ambiente. Os autores ainda afirmam que estes poluentes contaminam de maneira instantânea águas superficiais e subterrâneas e os ecossistemas presentes nestas, prejudicando a estabilidade da biota na região.

As mudanças percebidas na coloração da água são mostradas na figura 6 , onde 56 indivíduos $(77 \%)$ acreditam que houve mudança na coloração observada, 16 indivíduos $(22 \%)$ não percebeu modificação na coloração da água do rio. A maioria das pessoas que acreditam que houve modificação na coloração afirmaram que a mesma estava tomando tons mais escuros, isto é, ficando mais turva.

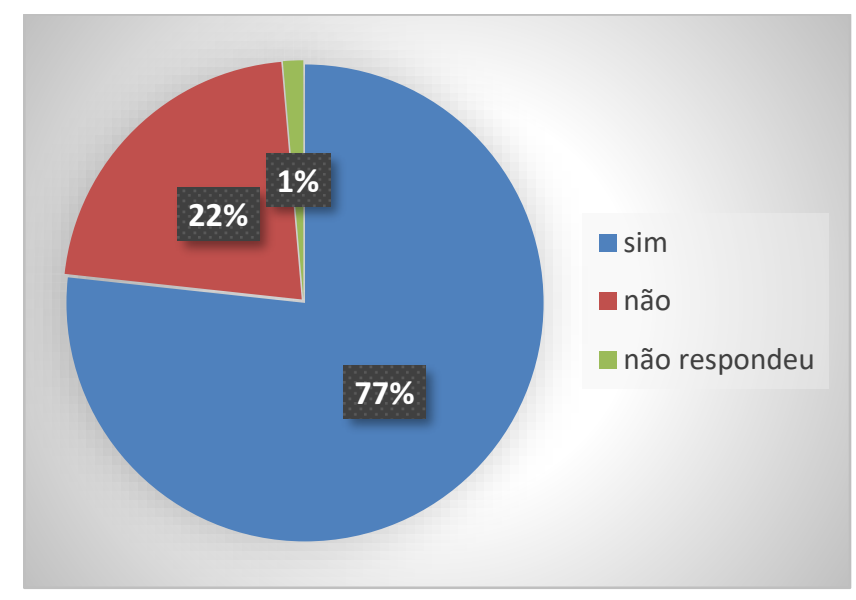

Figura 6: Mudança na coloração da água percebida pelos moradores. Fonte: Autores.

Segundo Renovato, Sena e Silva (2013), a turbidez do corpo hídrico é gerada a partir da quantidade de sólidos em suspensão. $\mathrm{O}$ aumento da turbidez afeta diretamente a dinâmica das cadeias tróficas, tendo em vista que dificulta o processo de penetração de luz (AZOLLINI, 2002).

\section{CONCLUSÕES/RECOMENDAÇÕES}

Este trabalho apresentou os resultados obtidos a partir da pesquisa aplicada com os habitantes de áreas próximas ao rio Ouricurí em Capanema-PA. Os resultados obtidos mostram haver alguns indicadores de que demonstram modificações na fauna e flora ao longo deste rio urbano. No que tange a quantidade de moradia próxima às margens, a maioria dos habitantes afirmou ter havido um crescimento nos últimos anos. 


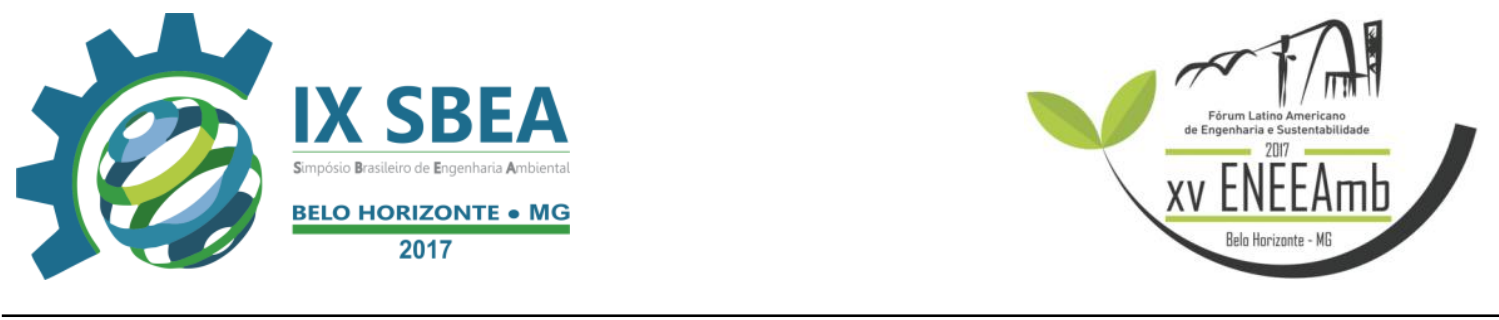

A maioria das entrevistas também indicou significativa depreciação na biodiversidade (quantidade de peixes observados e vegetação). A maioria dos entrevistados demostrou não possuir conhecimento com relação às causas da diminuição de espécies de fauna aquática.

\section{REFERÊNCIAS BIBLIOGRÁFICAS}

ALMEIDA, L. Q. Vulnerabilidades socioambientais de rios urbanos: bacia hidrográfica do rio Maranguapinho, região metropolitana de Fortaleza, Ceará. Rio Claro, 2010. 278f. Doutorado em Geografia. Universidade Estadual Paulista Júlio de Mesquita Filho, UNESP, Brasil.

AZZOLINI, J. C. Contribuição da poluição física, química e bioquímica nas águas do rio do peixe pelo afluente rio do tigre. 2002. 124 p. Dissertação (Mestrado em Engenharia da Produção) - Universidade Federal de Santa Catarina, Florianópolis, 2002. Disponível em: Acesso em: <https://repositorio.ufsc.br/bitstream/handle/123456789/82336/192519.pdf?sequence=1 >. 30 mai. 2017.

GUEDES, J. A. POLUIÇÃO DE RIOS EM ÁREAS URBANAS. Ateliê Geográfico, Universidade Federal de Goiás-UFG, v. 5, p. 212-226, 2011.

HERCULANO, S. S.; SILVA, J. R. RIOS URBANOS, MICROBACIAS E SUAS GENTES. Revista VITAS - Visões Transdisciplinares sobre Ambiente e Sociedade, Niterói, Ano V, No 9, fevereiro de 2015.

IBGE - Instituto Brasileiro de Geografia e Estatística. Disponível em: $<$ http://cidades.ibge.gov.br/painel/historico.php?lang=\&codmun=150220\&search=para| capanema|infograficos:-historico>. Acesso em: 30 mai. 2017.

KAMOGAWA, L. F. O. Crescimento Econômico, Uso dos Recursos Naturais e Qualidade Ambiental: Uma aplicação do modelo EKC no Brasil. Piracicaba, 2003. 121f. Mestrado em Economia Aplicada. Universidade de São Paulo, USP, Brasil.

LAKATOS, E. M.; MARCONI, M. A. Metodologia científica. 5. ed. ver. ampl. São Paulo: Atlas, 2008.

LIMA, L. D. B. Dos trilhos às rodas: histórias e memórias de Capanema. 1 ed. Belém, PA: Paka-Tatu, 2015.

MARTINS, M. L. M. R. Moradia e Mananciais: tensão e diálogo na metrópole. São Paulo: FAUUSP/FAPESP, 2006. 


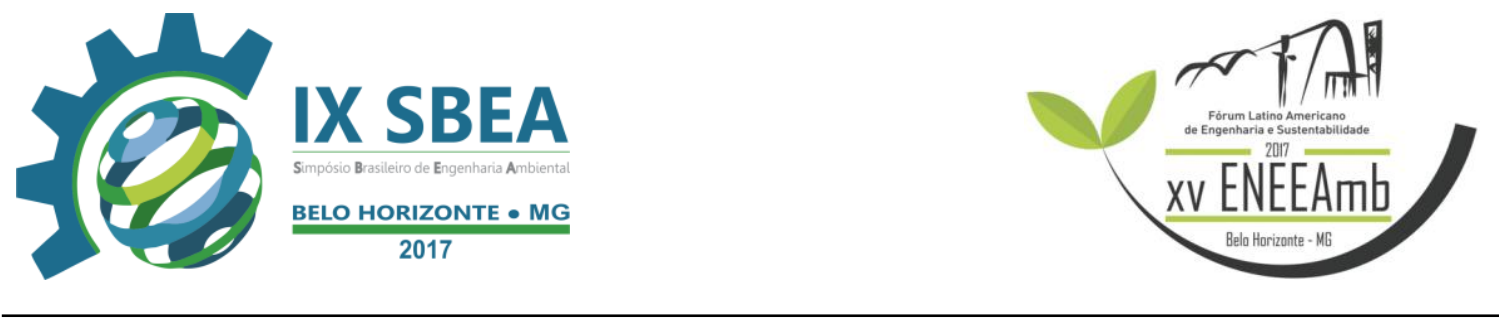

MONTANHA, F. P. et al. Degradação de Ambientes Aquáticos por Exposição à Compostos Químicos. Revista Científica Eletrônica de Medicina Veterinária, v. 1, p. 1$12,2011$.

MUCELIN, C. A.; BELLINI, L. M. Lixo e impactos ambientais perceptíveis no ecossistema urbano. Sociedade \& natureza, Universidade Federal de Uberlândia, v. 20, p. 111-124, 2008.

RENOVATO; D. C. C.; SENA, C. P. S. e SILVA, M. M. F. Análise de parâmetros físico-químicos das águas da barragem pública da cidade de Pau dos Ferros $(\mathrm{RN})-\mathrm{ph}$, cor, turbidez, acidez, alcalinidade, condutividade, cloreto e salinidade. In: IX Congresso de Iniciação Científica do IFRN. 2013. Disponível em: http://www2.ifrn.edu.br/ocs/index.php/congic/ix/paper/viewFile/1119/61 Acesso em: 30 mai. 2017.

SOARES, L. C. Biologia e Biodiversidade. 1. ed. Maringá: Cesumar, 2012. v. 1. 216p.

SOUZA, Geisa Bethânia Nogueira. Degradação ambiental: ocupação do solo na várzea do rio Ouricuri, Capanema (Pa). In: SIMPÓSIO BRASILEIRO DE GEOGRAFIA FÍSICA APLICADA, (10.), 2003, Rio de Janeiro. Anais... Rio de Janeiro: UFRJ, 2003.

SOUZA, J. R.; MORAES, M. E. B.; SONODA, S. L.; SANTOS, H. C. R. G. A Importância da Qualidade da Água e os seus Múltiplos Usos: Caso do Rio Almada, Sul da Bahia, Brasil. Revista Eletrônica do Prodema, Fortaleza, v. 8, p. 26-45, 2014.

TUCCI, C. E. M. Água no Meio Urbano. In: Aldo da Cunha Rebouças; Benedito Braga; José Galizia Tundisi. (Org.). Águas Doces no Brasil. 1ed.São Paulo: Escriuras, 1998, v. 1, p. 475-508. 